\title{
Combination therapy of oral hypoglycemic agents in patients with type 2 diabetes mellitus
}

\author{
Min Kyong Moon ${ }^{1}$, Kyu Yeon Hur ${ }^{2}$, Seung-Hyun Ko³, Seok-O Park ${ }^{4}$, Byung-Wan Lee ${ }^{5}$, Jin Hwa Kim ${ }^{6}$, \\ Sang Youl Rhee ${ }^{7}$, Hyun Jin Kim ${ }^{8}$, Kyung Mook Choi ${ }^{9}$, Nan-Hee Kim ${ }^{9}$, and on behalf of the Committee of \\ Clinical Practice Guidelines of the Korean Diabetes Association
}

\begin{abstract}
${ }^{1}$ Department of Internal Medicine, Seoul Metropolitan Government Seoul National University Boramae Medical Center, Seoul; ${ }^{2}$ Division of Endocrinology and Metabolism, Department of Internal Medicine, Samsung Medical Center, Sungkyunkwan University School of Medicine, Seoul; ${ }^{3}$ Division of Endocrinology and Metabolism, Department of Internal Medicine, College of Medicine, the Catholic University of Korea, Seoul; ${ }^{4}$ Department of Internal Medicine, Gwangmyeong Sungae Hospital, Gwangmyeong; ${ }^{5}$ Division of Endocrinology and Metabolism, Department of Internal Medicine, Yonsei University College of Medicine, Seoul; ${ }^{6}$ Division of Endocrinology and Metabolism, Department of Internal Medicine, Chosun University College of Medicine, Gwangju; ${ }^{7}$ Department of Endocrinology and Metabolism, Kyung Hee University School of Medicine, Seoul; ${ }^{8}$ Division of Endocrinology and Metabolism, Department of Internal Medicine, Chungnam National University School of Medicine, Daejeon; ${ }^{9}$ Division of Endocrinology and Metabolism, Department of Internal Medicine, Korea University College of Medicine, Seoul, Korea
\end{abstract}

Received: September 28, 2017 Accepted: October 20, 2017
The Korean Diabetes Association (KDA) recently updated the Clinical Practice Guidelines on antihyperglycemic agent therapy for adult patients with type 2 diabetes mellitus ( $\left.\mathrm{T}_{2} \mathrm{DM}\right)$. In combination therapy of oral hypoglycemic agents (OHAs), general recommendations were not changed from those of the $2015 \mathrm{KDA}$ guidelines. The Committee on Clinical Practice Guidelines of the KDA has extensively reviewed and discussed the results of meta-analyses and systematic reviews of effectiveness and safety of OHAs and many clinical trials on Korean patients with T2DM for the update of guidelines. All OHAs were effective when added to metformin or metformin and sulfonylurea, although the effects of each agent on body weight and hypoglycemia were different. Therefore, selection of a second agent as a metformin add-on therapy or third agent as a metformin and sulfonylurea add-on therapy should be based on the patient's clinical characteristics and the efficacy, side effects, mechanism of action, risk of hypoglycemia, effect on body weight, patient preference, and combined comorbidity. In this review, we address the results of meta-analyses and systematic reviews, comparing the effectiveness and safety among OHAs. It will help to choose the appropriate drug for an individual patient with T2DM.

Keywords: Diabetes mellitus, type 2; Efficacy; Oral hypoglycemic agents; Practice guideline

\author{
Correspondence to \\ Nan-Hee Kim, M.D. \\ Division of Endocrinology and Metabolism, Department of Internal Medicine, Korea \\ University Ansan Hospital, 123 Jeokgeum-ro, Danwon-gu, Ansan 15355, Korea \\ Tel: $+82-31-412-4274$ \\ Fax: $+82-31-412-6770$ \\ E-mail:nhkendo@gmail.com
}

This manuscript is simultaneously published in the Diabetes Metabolism Journal and the Korean Journal of Internal Medicine by the Korean Diabetes Association and the Korean Association of Internal Medicine. 


\section{INTRODUCTION}

The Korean Diabetes Association (KDA) has stated that the prevalence of diabetes among adults 30 years or older was about $13.7 \%$ in 2014 [1]. Good glycemic control is well known to be the best way to prevent chronic complications of diabetes [2], but the control rate of glycemia among those with diagnosed diabetes is only $23.3 \%$ for a target goal of glycosylated hemoglobin (HbAlc) $<6.5 \%$ or $43.5 \%$ for $<7.0 \%[1,3]$. Because about $80 \%$ of people with diabetes are treated with oral hypoglycemic agents (OHAs) [1,3], it is very important to establish appropriate guidelines for the selection of OHAs. Moreover, most OHAs were developed in Western countries, so the efficacy and safety data of OHAs were provided from the clinical studies performed on Caucasians. The pharmacodynamics and pharmacokinetics of specific OHAs can be different among ethnicities. Therefore, it is very important to get specifically Korean data. Fortunately, many clinical trials on Korean patients with diabetes have been conducted, and the results have been published in the past few years. For this 2017 position statement regarding pharmacological therapies for non-pregnant adult patients with type 2 diabetes mellitus (T2DM), extensive review of scientific evidence, including the results of clinical trials of OHAs for Koreans was performed by the Committee on Clinical Practice Guidelines of the KDA. In this review, we describe the results of systematic reviews and the considerations during the process and propose appropriate combination therapy of OHAs for Korean patients with T2DM.

\section{RECOMMENDATIONS}

\section{Principles of treatment with antihyperglycemic agents}

1. Metformin is the preferred initial oral antihyperglycemic agent $[\mathrm{A}]$.

2. If metformin is contraindicated or intolerable as the initial treatment, then another class of antihyperglycemic agent can be used, depending on the clinical situation [E].

3. If monotherapy fails to achieve the glycemic goal, then combination therapy using a second agent with a different mechanism of action should be initiated $[\mathrm{A}]$.
4. Dual combination therapy can be used as the initial management strategy, depending on the patient [B].

5. Although the maximal dosage of a single oral agent may be prescribed, early initiation of combination therapy is suitable after considering the glucose-lowering efficacy and side-effects of the drug [B].

6. When selecting a class of antihyperglycemic agents for combination therapy, the glucose-lowering efficacy, risk of hypoglycemia, body weight gain, and cardiovascular benefits associated with the drugs are preferentially considered [E].

7. The different mechanisms of action, drug interactions, and patient preferences for combination therapy with more than two classes of antihyperglycemic agents should be considered [C].

\section{WHAT IS THE BEST DRUG AS ADD-ON THERA- PY TO METFORMIN?}

There are six major classes of antidiabetic agents that can be combined with metformin. They are sulfonylurea (SU), thiazolidinediones (TZDs), dipeptidyl peptidase-4 inhibitors (DPP4i), sodium-glucose cotransporter-2 inhibitors (SGLT2i), glucagon-like peptide-1 receptor agonists, and insulin. The American Diabetes Association does not prioritize any specific medication and recommends physicians to choose one based on their efficacy, hypoglycemic risk, weight effects, side-effects, and cost [4]. However, the American Association of Clinical Endocrinologists recommended the SGLT2i first, followed by DPP4i, TZD, $\alpha$-glucosidase inhibitors, and SU among the OHAs, mainly based on the weight-reducing effect [5]. In this paper, we provide a comparative review among the OHAs based on meta-analyses and suggest a guide to select one as a first-combination medication with metformin.

\section{Comparison of SU and DPP4i as an add-on therapy to metformin}

Several meta-analyses compared SU and DPP4i as an add-on therapy to metformin [6-11]. DPP4i lowered HbAic levels to a similar extent $[6,7]$ or slightly less (HbAic difference $0.08 \%$ to $0.21 \%$ ) $[8,9,11]$ compared to SU when added to metformin (Table 1). A meta-analysis comparing DPP4i with $\mathrm{SU}$ as an add-on therapy to 
Table 1. Summary of meta-analyses reviewed for comparison of sulfonylurea and DPP-4 inhibitor as an add-on therapy to metformin

\begin{tabular}{|c|c|c|}
\hline Study & Included trials $(n)$ & Results \\
\hline $\begin{array}{l}\text { Palmer et al. } \\
(2016)[8]\end{array}$ & $\begin{array}{l}301 \text { RCTs comparing } 2 \\
\text { glucose-lowering drug } \\
\text { classes for treatment of } \\
\text { T2DM for } 24 \text { weeks' or } \\
\text { longer duration }\end{array}$ & $\begin{array}{l}\text { No significant differences in the associations between any of } 9 \text { available } \\
\text { classes of glucose-lowering drugs (alone or in combination) and the risk of } \\
\text { cardiovascular or all-cause mortality } \\
\text { All drugs were effective when added to metformin. }\end{array}$ \\
\hline $\begin{array}{l}\text { Mishriky et al. } \\
(2015)[7]\end{array}$ & $\begin{array}{l}16 \text { RCTs comparing } \\
\text { DPP4i to SU as add-on } \\
\text { therapy to metformin }\end{array}$ & $\begin{array}{l}\text { A significantly greater reduction in HbA1c from baseline to } 12 \text { weeks with } \\
\text { SU vs. DPP4i (MD, 0.21\%; 95\% CI, 0.06-0.35) } \\
\text { No significant difference at } 52 \text { and } 104 \text { weeks (MD, 0.06\%; 95\% CI, 0.03-0.15; } \\
\text { and MD, 0.02\%; 95\% CI, 0.13-0.18, respectively) } \\
\text { SU was associated with weight gain and DPP4i with weight loss at all } \\
\text { time-points. } \\
\text { The incidence of hypoglycemia at 12, 52, and } 104 \text { weeks was significantly } \\
\text { greater with SU (20\%, 24\%, and } 27 \% \text { respectively) compared to DPP4i } \\
\text { (6\%,3\%, and } 4 \% \text { respectively). }\end{array}$ \\
\hline $\begin{array}{l}\text { Zhou et al. } \\
(2016)[9]\end{array}$ & $\begin{array}{l}14 \text { RCTS comparing } \\
\text { DPP4i to SU }(5,480 \\
\text { patients randomised to } \\
\text { DPP4i and } 5,214 \text { patients } \\
\text { randomised to } \mathrm{SU})\end{array}$ & $\begin{array}{l}\text { Compared with SU, DPP4i were associated with a smaller decline in HbA1c } \\
\text { (WMD, weighted mean differences, } 0.08 \% ; 95 \% \mathrm{CI}, 0.03-0.14 ; p=0.001 \text { ), } \\
\text { and resulted in weight loss of } 1.945 \mathrm{~kg}(95 \% \mathrm{CI},-2.237 \text { to }-1.653 ; p<0.0001) \text {. } \\
\text { The effect of DPP4i lowering FPG was inferior to that of } \mathrm{SU} \text { (WMD, o.268 } \\
\text { mmol/L; 95\% CI, 0.151-0.385; } p<0.0001 \text { ), and similar in reducing PPG } \\
\text { (WMD, } 0.084 \mathrm{mmol} / \mathrm{L} ; 95 \% \mathrm{CI},-0.701 \text { to } 0.869 ; p=0.833 \text { ). } \\
\text { DPP4i had a favorable insulin resistance and low risk for AE and } \\
\text { hypoglycemia. }\end{array}$ \\
\hline $\begin{array}{l}\text { Foroutan et al. } \\
(2016)[10]\end{array}$ & $\begin{array}{l}\text { 10 RCTs comparing } \\
\text { DPP4i to SU as add-on } \\
\text { therapy to metformin } \\
\text { (10,139 subjects) }\end{array}$ & $\begin{array}{l}\text { DPP4i compared to SU produced a non-significant difference in } \mathrm{HbA1c} \% \\
\text { change whereas a significant decrease in the rate of hypoglycemic events } \\
\text { was observed in favor of DPP4i. } \\
\text { DPP4i was associated with significant weight loss }(2.2 \mathrm{~kg}) \text { compared to SU. }\end{array}$ \\
\hline
\end{tabular}

RCT, randomized controlled trial; T2DM, type 2 diabetes mellitus; DPP4i, dipeptidyl peptidase-4 inhibitor; SU, sulfonylurea; MD, mean difference; CI, confidence interval; HbAic, glycosylated hemoglobin; WMD, weighed mean difference; FPG, fasting plasma glucose; PPG, postprandial glucose; AE, adverse events.

metformin showed a significantly greater reduction in $\mathrm{HbA1c}$ from baseline to 12 weeks with SU versus DPP4i (mean difference, $0.21 \%$ ) but no significant difference at 52 and 104 weeks [7]. As we expected, DPP4i was associated with a lower risk of hypoglycemia (odds ratio [OR], 0.12) and weight gain (-0.58 kg) compared to SU. In terms of cardiovascular (CV) outcome, there were no significant differences between DPP4i and SU for CV mortality, all-cause mortality, serious adverse events, or myocardial infarction, but DPP4i and metformin exhibited a lower risk of stroke compared with a combination of SU and metformin (OR, 0.47; 95\% confidence interval [CI], 0.23 to 0.95 ) in a meta-analysis of 301 randomized clinical trials involving 118,094 patients published in
JAMA in 2016 [8]. In a cohort study of 349,476 patients with T2DM, using the Korean National Health Insurance Service (NHIS) claims database, however, treatment with $\mathrm{SU}+$ metformin was associated with increased total cardiovascular disease (CVD) (hazard ratio [HR], 1.20; 95\% CI, 1.09 to 1.32), myocardial infarction (HR, 1.41; 95\% CI, 1.04 to 1.91), and ischemic stroke risks (HR, 1.51; 95\% CI, 1.28 to 1.79) compared with a DPP $4 \mathrm{i}+$ metformin regimen [12]. Because there is no randomized controlled prospective study for $\mathrm{CV}$ outcomes for $\mathrm{SU}$, and all possible confounders could not be adjusted in observational studies, these results should be interpreted with caution. However, DPP4i is at least not inferior to $\mathrm{SU}$ in terms of efficacy and superior in terms of safety. 
Table 2. Between-group differences in the change in HbA1c for comparison of SU and SGLT2i as an add-on therapy to metformin [13]

\begin{tabular}{|c|c|c|c|c|c|c|}
\hline Intervention & Trials & Duration, wk & $\begin{array}{c}\text { No. of } \\
\text { patients }\end{array}$ & $\begin{array}{l}\text { HbA1c } \\
\text { SGLT2i }\end{array}$ & $\begin{array}{l}\text { HbAic } \\
\text { control }\end{array}$ & $\begin{array}{l}\text { Change in } \mathrm{HbAlc} \\
\text { (mean difference) }\end{array}$ \\
\hline \multirow{4}{*}{$\begin{array}{l}\text { Metformin + } \\
\text { SGLT2i vs. Met- } \\
\text { formin + SU }\end{array}$} & Cefalu et al. (2013) [14] & 104 & 1,452 & 7.8 & 7.8 & $-0.19(-0.29$ to -0.09$)$ \\
\hline & Nauck et al. (2011) [15] & 208 & 814 & $7 \cdot 7$ & $7 \cdot 7$ & $-0.30(-0.79$ to 0.19$)$ \\
\hline & Ridderstrale et al. (2014) [16] & 104 & 1,549 & $7 \cdot 9$ & $7 \cdot 9$ & $-0.11(-0.19$ to -0.03$)$ \\
\hline & Total & & & & & $-0.15(-0.21$ to -0.08$)$ \\
\hline
\end{tabular}

HbA1c, glycosylated hemoglobin; SU, sulfonylurea; SGLT2i, sodium-glucose cotransporter-2 inhibitor.

\section{Comparison of SU and SGLT2i as an add-on therapy to metformin}

Two meta-analyses showed that SGLT2i as an add-on therapy to metformin lowered HbAlc levels more (0.15\%) than SU did (Table 2) [6,13-16]. In addition, SGLT2i was associated with a lower risk of hypoglycemia and less body weight gain $[6,8,13]$. Because these analyses included only three studies, and differences in efficacy among SGLT2i results were reported [17], we need to wait for further studies.

From pooled data from four empagliflozin phase III trials, adjusted mean differences versus placebo in change from baseline in $\mathrm{HbAlc}$ were $-0.61 \%$ (baseline, $7.91 \%$ ) and $-0.75 \%$ (baseline, 7.94\%) and in weight were $-1.4 \mathrm{~kg}$ (baseline, 70.3 kg) and -1.5 kg (baseline, 72.1 kg) with empagliflozin 10 and $25 \mathrm{mg}$, respectively, when combined with metformin in Asian patients with T2DM [18]. These results were consistent with previous empagliflozin phase III trials in which at week 24, adjusted mean \pm SE changes from baseline in $\mathrm{HbA1c}$ were $-0.70 \%$ $\pm 0.05 \%$ with empagliflozin $10 \mathrm{mg}$, and $-0.77 \% \pm 0.05 \%$ with empagliflozin $25 \mathrm{mg}$ [19]. In terms of ipragliflozin and metformin combination therapy in Korean patients with T2DM inadequately controlled with metformin, adjusted mean differences versus placebo in change from baseline in $\mathrm{HbAlc}$ were -0.60\% (baseline, 7.67\%) and in weight were $-1.53 \mathrm{~kg}$ (baseline, $68.12 \mathrm{~kg}$ ) with ipragliflozin [20]. These results suggested that the efficacy of SGLT2i in Korean patients with T2DM as an add-on therapy to metformin would be similar to Caucasian populations.

\section{Comparison of DPP4i and SGLT2i as an add-on ther- apy to metformin}

A meta-analysis of 4 clinical studies showed that SGLT2i as an add-on therapy to metformin lowered HbAic levels more (0.17\%) and body weight much more than DPP4i (Table 3) [13,21-24]. In a meta-analysis published in JAMA in 2016, the rate of treatment failure was significantly lower with SGLT2i (OR, 0.68; 95\% CI, o.48 to 0.96) and higher with DPP4i (OR, 1.37; 95\% CI, 1.07 to 1.76) than with SU [8]. In addition, both DPP4i and SGLT2i were associated with a lower risk of hypoglycemia compared to $\mathrm{SU}$, and the ORs of both drugs were similar to $0.12[19]$.

The CV safety of DPP4i has been demonstrated through the Saxagliptin Assessment of Vascular Outcomes Recorded in Patients with Diabetes MellitusThrombolysis in Myocardial Infarction 53 (SAVOR-TIMI 53), the Examination of Cardiovascular Outcomes with Alogliptin versus Standard of Care (EXAMINE), and the Trial Evaluating Cardiovascular Outcomes with Sitagliptin (TECOS) trials [25-27]. However, these trials failed to show the CV benefits. In contrast, in the Cardiovascular Outcome Event Trial in Type 2 Diabetes Mellitus Patients (EMPA-REG) Outcome trial, patients who received empagliflozin rather than a placebo had lower rates of primary composite CV outcome (10.5\% vs. $12.1 \%$ in the placebo group; $14 \%$ relative risk reduction), death from CV causes (3.7\%, vs. 5.9\%, respectively; $38 \%$ relative risk reduction), hospitalization for heart failure (2.7\% and $4.1 \%$, respectively; $35 \%$ relative risk reduction), and death from any cause $5.7 \%$ and $8.3 \%$, respectively; $32 \%$ relative risk reduction) [28]. Moreover, empaglifloz- 
Table 3. Between-group differences in the change in HbA1c for comparison of DPP4i and SGLT2i as an add-on therapy to metformin [13]

\begin{tabular}{|c|c|c|c|c|c|c|}
\hline Intervention & Trials & $\begin{array}{l}\text { Duration, } \\
\text { wk }\end{array}$ & $\begin{array}{c}\text { No. } \\
\text { of patients }\end{array}$ & $\begin{array}{l}\text { HbA1c } \\
\text { SGLT2i }\end{array}$ & $\begin{array}{l}\text { HbAic } \\
\text { control }\end{array}$ & $\begin{array}{l}\text { Change of HbAic } \\
\text { (mean difference) }\end{array}$ \\
\hline \multirow{4}{*}{$\begin{array}{l}\text { Metformin + SGLT2i } \\
\text { vs. Metformin + } \\
\text { DPP4i }\end{array}$} & $\begin{array}{l}\text { Lavalle-Gonzalez et } \\
\text { al. (2013) [21] }\end{array}$ & 26 & 1,284 & $7 \cdot 9$ & $7 \cdot 9$ & $-0.12(-0.23$ to -0.01$)$ \\
\hline & $\begin{array}{l}\text { Rosenstock et al. } \\
\text { (2012) [22] }\end{array}$ & 12 & 451 & $7 \cdot 7$ & $7 \cdot 6$ & $-0.18(-0.40$ to 0.04$)$ \\
\hline & $\begin{array}{l}\text { Rosenstock et al. } \\
(2015)[23]\end{array}$ & 24 & 534 & 8.9 & 9.0 & $-0.32(-0.53$ to -0.11$)$ \\
\hline & $\begin{array}{l}\text { DeFronzo et al. } \\
(2015)[24]\end{array}$ & 52 & 899 & 8.0 & 8.0 & $-0.16(-0.33$ to 0.01$)$ \\
\hline
\end{tabular}

HbA1c, glycosylated hemoglobin; DPP4i, dipeptidyl peptidase-4 inhibitor; SGLT2i, sodium-glucose cotransporter-2 inhibitor.

in was associated with slower progression of kidney disease and lower rates of clinically relevant renal events [29]. In subsequent the Canagliflozin Cardiovascular Assessment Study (CANVAS) and CANVAS-Renal trials, canagliflozin was also associated with lower rates of CVD and renal outcome [30].

From these results, it appears that SGLT2i can be superior to DPP4i. However, there are a few things to consider before deciding which drug is better. First, adverse reactions of SGLT2i such as urogenital infection, euglycemic diabetic ketoacidosis, or dehydration may limit the use of SGLT2i. Second, DPP4i have been reported to be more effective in lowering blood glucose levels in Asians, including Koreans, than in Caucasian [31]. A meta-analysis revealed that DPP4i lowered HbAlc to a greater extent in studies with $\geq 50 \%$ of Asian participants (weighted mean difference [WMD], -0.92\%; 95\% CI, -1.03 to -0.82 ) than in studies with $<50 \%$ Asian participants (WMD, $-0.65 \%$; $95 \% \mathrm{CI},-0.69$ to -0.60$)$. The between-group difference was $-0.26 \%$ (95\% CI, -0.36 to $-0.17 ; p<0.001)[11]$. In trials with oral combination therapy, $\mathrm{HbA1c}$ decreased by $0.66 \%$ in the non-Asian dominant studies, whereas it decreased by $0.85 \%$ in the Asian-dominant studies. In fact, in clinical studies conducted in Korea, the HbA1c-lowering effect of DP$\mathrm{P} 4 \mathrm{i}$ was $0.8 \%$ to $1.2 \%$ after 24 weeks of treatment with around $8 \%$ of baseline $\mathrm{HbA1c}$ [32-34]. These results are comparable to the efficacy of the SGLT2i [20].

Therefore, it is difficult to give a comprehensive answer about whether SGLT2i or DPP4i should be prefera- ble in combination therapy with metformin. The choice of an adequate drug should be decided in consideration of the individual characteristics of the patient and the response to the drug.

\section{Comparison of TZD and SU or DPP4i as an add-on therapy to metformin}

A meta-analysis showed that TZD lowered HbArc levels to similarly to SU and slightly more (0.12\%) than DP$\mathrm{P} 4 \mathrm{i}$ when added to metformin [6]. TZD significantly increased body weight compared to SU and DPP4i [6]. This meta-analysis included only four randomized clinical trials and 674 participants, so the strength of evidence was moderate. In addition, as previously commented, it should be considered that the glucose-lowering efficacy of DPP4i can be higher in Asians than in Caucasians. In the study comparing the efficacy of vildagliptin (50 mg twice daily) to that of pioglitazone ( $15 \mathrm{mg}$ once daily) as an add-on treatment to metformin in Korean patients with $\mathrm{T}_{2} \mathrm{DM}$, the efficacy of vildagliptin to lower the HbArc level was not inferior to that of pioglitazone, and vildagliptin had beneficial effects on postprandial glucose levels compared to pioglitazone [35]. On the other hand, in the study comparing the efficacy of lobeglitazone and pioglitazone as add-ons to metformin, both of them decreased HbAic by $0.74 \%$ at week 24 [36]. Therefore, the efficacy difference between DPP4i and TZD might be less significant in Koreans.

In the PROspective pioglitAzone Clinical Trial In macroVascular Events (PROactive Study), pioglitazone 
reduced the composite of all-cause mortality, non-fatal myocardial infarction, and stroke in patients with T2DM who have a high risk of macrovascular events [37]. In addition, in a cohort study of 349,476 patients with T2DM, using the Korean NHIS claims database, treatment with pioglitazone + metformin was associated with decreased total CVD (HR, 0.89; $95 \%$ CI, 0.81 to 0.99 ), ischemic stroke risks (HR, 0.81; 95\% CI, 0.67 to 0.99 ), and increased heart failure risks (HR, 4.81; 95\% CI, 3.53 to 6.56) compared with a $\mathrm{DPP}_{4} \mathrm{i}+$ metformin combination [12]. It has been reported that TZDs have long-term benefits in glycemic control by augmenting insulin sensitivity and preserving $\beta$-cell function [38-40]. In the study that compared the efficacy of TZDs to other oral glucose-lowering medications in maintaining long-term glycemic control in $\mathrm{T} 2 \mathrm{DM}$, the cumulative incidence of monotherapy failure at 5 years was $15 \%$ with rosiglitazone, $21 \%$ with metformin, and 34\% with glyburide [38]. Therefore, it is difficult to say that either DPP4i or TZD is superior, and appropriate drugs should be selected after consideration of individual status.

\section{TRIPLE ORAL AGENT COMBINATION THERAPY}

Five meta-analyses were performed to evaluate the comparative effectiveness and safety of triple combination therapy (drugs added to metformin + SU) (Table 4) [8,41-44]. The addition of a third drug to metformin + SU therapy was statistically and clinically more effective at reducing HbAic than dual therapy with metformin + SU. In these analyses, the HbArc-lowering effect was consistently better when combined with TZD (-0.93\%) and SGLT2i (-0.86\%) than with DPP4i (-0.68\%) or acarbose $(-0.60 \%)$. When triple therapies are compared with each other; however, there are no statistically significant differences with regard to change in HbAic for any of the comparisons. In a network meta-analysis including 20 randomized controlled trials, canagliflozin and TZDs reduced $\mathrm{HbA1c}$ by $\sim 1 \%$ (range, $0.98 \%$ to $1.2 \%$ ), whereas acarbose, dapagliflozin, empagliflozin, and DPP4i reduced $\mathrm{HbA1c}$ by $0.60 \%$ to $0.76 \%$ when compared to placebo/control [44]. Interestingly, a triple combination of metformin + TZD + DPP4i showed no improvement in HbAic compared to metformin + SU [41]. In terms of weight, as we can expect, the SGLT2i was associated with significant weight loss, and the TZDs and DPP4i resulted in significant weight gain compared with placebo/ control. In terms of hypoglycemia, although the results are different among the analyses, TZDs as add-on therapy to metformin + SU were associated with significantly higher rates of hypoglycemia $[8,44]$. It seems there are no statistically significant differences in the risks of hypoglycemia among most triple therapies [41]. In terms of CV safety, there was no evidence of significantly different associations with CV mortality, all-cause mortality, or serious adverse events between any of the drug classes given as triple therapy [8]. From these analyses, the combination of metformin $+\mathrm{SU}+\mathrm{TZZ}$ is the best in lowering HbA1c, but it is the worst in weight gain and hypoglycemia. The combination of metformin $+\mathrm{SU}+$ SGLT2i is the second-best in lowering HbA1c, but it is the best in weight loss. The combination of metformin $+\mathrm{SU}+\mathrm{DPP} 4 \mathrm{i}$ is relatively weak in lowering HbA1c compared to metformin $+\mathrm{SU}+\mathrm{SGLT} 2 \mathrm{i}$ or metformin $+\mathrm{SU}$ + TZD. Therefore, SGLT2i is a reasonable option as a third agent added to metformin + SU. At this point, we have to consider that the efficacy of DPP4i can be higher in Asians. Actually, the addition of gemigliptin significantly reduced HbAic levels (0.87\% at week 24) compared with placebo in 219 Korean patients inadequately controlled with metformin and glimepiride [45]. In the other study, the addition of vildagliptin to metformin and SU decreased the adjusted mean HbAic levels by $1.19 \%$ at week 24 [32], and this reduction seems to be comparable to that of TZD or SGLT2i.

Because there were only limited data about the comparison of other triple combination therapies other than the addition of a third drug to metformin $+\mathrm{SU}$, the preceding descriptions about triple combination therapy need to be interpreted with care.

\section{CONCLUSIONS}

Both in metformin add-on and in metformin + SU addon, SGLT2i and TZD showed more efficacy than DPP4i or acarbose, but the actual difference was as small as $0.1 \%$ to $0.2 \%$ of HbArc. Although the difference is statistically significant, it does not seem to be clinically meaningful because usually the difference in HbAic of $\geq 0.3 \%$ is regarded as meaningful. In addition, dif- 
Table 4. Summary of meta-analyses reviewed for comparison of triple oral agent combination therapy

\begin{tabular}{|c|c|c|}
\hline Study & Included trials $(n)$ & Results \\
\hline $\begin{array}{l}\text { Palmer et al. } \\
(2016)[8]\end{array}$ & $\begin{array}{l}301 \text { RCTs comparing } 2 \\
\text { glucose-lowering drug } \\
\text { classes for treatment of } \\
\text { T2DM for } 24 \text { weeks' or } \\
\text { longer duration }\end{array}$ & $\begin{array}{l}\text { No significant differences in the associations between any of } 9 \text { available classes } \\
\text { of glucose-lowering drugs (alone or in combination) and the risk of } \\
\text { cardiovascular or all-cause mortality } \\
\text { All drugs were effective when added to metformin. }\end{array}$ \\
\hline $\begin{array}{l}\text { Mearns et al. } \\
(2015)[44]\end{array}$ & $\begin{array}{l}\text { 20 RCTs evaluating } 13 \\
\text { antihyperglycaemic } \\
\text { agents in adults with } \\
\text { T2DM experiencing poor } \\
\text { glycemic control despite } \\
\text { optimized metformin } \\
\text { and SU therapy }\end{array}$ & $\begin{array}{l}\text { Compared with placebo/control, all antihyperglycemic agents reduced HbAic } \\
\text { levels, albeit by differing magnitudes (o.6\% for acarbose to } 1.20 \% \\
\text { for liraglutide) } \\
\text { SGLT2i reduced weight (1.43-2.07 kg), whereas TZDs, glargine and sitagliptin } \\
\text { caused weight gain }(1.48-3.62 \mathrm{~kg}) \text { compared with placebo/control. } \\
\text { SGLT2i, rosiglitazone and liraglutide decreased SBP compared with placebo/ } \\
\text { control, pioglitazone, glargine and sitagliptin (2.41-8.88 mmHg) } \\
\text { Glargine, TZDs, liraglutide, sitagliptin, and canagliflozin increased } \\
\text { hypoglycemia risk compared with placebo/control (relative risk, } 1.92-7.47) \text {, } \\
\text { while glargine and rosiglitazone increased hypoglycemia compared with } \\
\text { most antihyperglycemic agents (relative risk, 2.81-7.47). } \\
\text { Canagliflozin increased the risk of genital tract infection by 3.9-fold compared } \\
\text { with placebo/control. }\end{array}$ \\
\hline $\begin{array}{l}\text { Downes et al. } \\
(2015)[41]\end{array}$ & $\begin{array}{l}27 \text { RCTs comparing } \\
\text { metformin }+ \text { SU dual } \\
\text { therapy to other triple } \\
\text { therapy combinations }\end{array}$ & $\begin{array}{l}\text { For HbAic reduction, all triple therapies were statistically superior to } \\
\text { metformin + SU dual therapy, except for metformin + TZD + DPP4i. } \\
\text { None of the triple therapy combinations demonstrated differences in HbA1c } \\
\text { compared with other triple therapies. } \\
\text { Metformin + SU + SGLT2i and metformin + SU + GLP-1RA resulted in } \\
\text { significantly lower body weight than metformin + SU + DPP4i, metformin + } \\
\text { SU + insulin and metformin + SU + TZDs; metformin + SU + DPP4i resulted } \\
\text { in significantly lower body weight than metformin + SU + insulin and } \\
\text { metformin + SU + TZD. } \\
\text { Metformin + SU + insulin, metformin + SU + TZD and metformin + SU + } \\
\text { DPP4i increased the odds of hypoglycaemia when compared to metformin + } \\
\text { SU. Metformin + SU + GLP-1RA reduced the odds of hypoglycemia compared } \\
\text { to metformin + SU + insulin. }\end{array}$ \\
\hline $\begin{array}{l}\text { Lee et al. (2016) } \\
{[42]}\end{array}$ & $\begin{array}{l}\text { 40 RCTS comparing dual } \\
\text { therapy to any triple } \\
\text { combinations } \\
(15,182 \text { participants })\end{array}$ & $\begin{array}{l}\text { Compared with none/placebo added to dual therapy, triple combination } \\
\text { therapy resulted in significant additional mean reductions in HbA1c from } \\
\text {-0.56\% (DPP4i) to -0.94\% (TZDs). } \\
\text { Insulin, TZD and SU were associated with less favourable weight change and } \\
\text { GLP-1RA and SGLT2i were associated with more favourable weight change } \\
\text { when compared with none/placebo added to dual therapy. } \\
\text { Compared with none/placebo added to dual therapy, the odds of hypoglycemia } \\
\text { were higher for DPP4i (1.95), SGLT2i (2.27), GLP-1RA (2.61), TZD (2.83), and } \\
\text { insulin (5.94). }\end{array}$ \\
\hline $\begin{array}{l}\text { Lozano-Ortega } \\
\text { et al. (2016) }[43]\end{array}$ & $\begin{array}{l}\text { 30 RCTs comparing } \\
\text { SGLT2i to other drugs as } \\
\text { add-on therapy to } \\
\text { metformin and SU }\end{array}$ & $\begin{array}{l}\text { The mean change (\%) in HbA1c levels compared to placebo was -0.86 for } \\
\text { SGLT2i, }-0.68 \text { for DPP4i, }-0.93 \text { for TZDs, and }-1.07 \text { for GLP-1RA, respectively. } \\
\text { Only SGLT2i and GLP-1RA led to a weight loss (-1.71 and }-1.14 \mathrm{~kg} \text {, respectively) } \\
\text { and decrease in SBP ( }-3.73 \text { and }-2.90 \mathrm{mmHg} \text {, respectively), while all other } \\
\text { treatments showed either an increase or no changes in weight or SBP. }\end{array}$ \\
\hline
\end{tabular}

RCT, randomized controlled trial; T2DM, type 2 diabetes mellitus; SU, sulfonylurea; HbA1c, glycosylated hemoglobin; SGLT2i, sodium-glucose cotransporter-2 inhibitor; TZD, thiazolidinedione; SBP, systolic blood pressure; DPP4i, dipeptidyl peptidase-4 inhibitor; GLP-ıRA, glucagon-like peptide-1 receptor agonist. 
ferences in efficacy or safety of each drug even in the same class have been reported, and the response to individual drugs can be different, depending on ethnicities and/or individual characteristics. Therefore, the choice of drug requires many aspects of consideration, such as patient preferences, patient characteristics, comorbidity, and drug characteristics, with the goal of reducing blood glucose levels and side effects, including weight gain and hypoglycemia.

\section{Conflict of interest}

No potential conflict of interest relevant to this article was reported.

\section{Acknowledgments}

Financial support for the development of these guidelines was provided by the Korean Diabetes Association (KDA) operating budget; there was no support or involvement from industry sources.

This position statement on antihyperglycemic agent therapy was written by the KDA Committee of Clinical Practice Guidelines. We gratefully acknowledge the following experts who provided a critical review and discussion of this update: Tae-Nyun Kim, Inje University College of Medicine, Busan; Yong-ho Lee, Severance Hospital, Yonsei University College of Medicine, Seoul; Jin-Hwa Kim, Chosun University Hospital, Chosun University College of Medicine, Gwangju; Eun-Gyoung Hong, Hallym University Dongtan Sacred Heart Hospital, Hwaseong; Jaetaek Kim, Chung-Ang University College of Medicine, Seoul; Won-Young Lee, Kangbuk Samsung Hospital, Sungkyunkwan University School of Medicine, Seoul; Bokrye Song, College of Medicine, Seoul St. Mary's Hospital, The Catholic University of Korea, Seoul; Ji Young Kim, Samsung Medical Center, Sungkyunkwan University School of Medicine, Seoul; Dong Hee Yang, Inje University Ilsan Paik Hospital, Goyang; Taeyoung Yang, Taeyoung 21 Hospital, Gwangju; and Hyeongjin Kim, Kim HJ Medical Clinic, Paju, Korea.

\section{REFERENCES}

1. Korean Diabetes Association. Diabetes Fact Sheet in Korea 2016 [Internet]. Seoul (KR): Korean Diabetes
Association, c2011 [cited 2017 Oct 20]. Available from: http://www.diabetes.or.kr/pro/news/admin.php?category=A\&code=admin\&number=1428\&mode=view.

2. Nathan DM; DCCT/EDIC Research Group. The diabetes control and complications trial/epidemiology of diabetes interventions and complications study at 30 years: overview. Diabetes Care 2014;37:9-16.

3. Ha KH, Kim DJ. Current status of managing diabetes mellitus in Korea. Korean J Intern Med 2016;31:845-850.

4. American Diabetes Association. 8. Pharmacologic approaches to glycemic treatment. Diabetes Care 2017;40(Suppl 1):S64-S74.

5. Garber AJ, Abrahamson MJ, Barzilay JI, et al. Consensus statement by the American Association of Clinical Endocrinologists and American College of Endocrinology on the comprehensive type 2 diabetes management algorithm: 2017 executive summary. Endocr Pract 2017;23:207238.

6. Maruthur NM, Tseng E, Hutfless S, et al. Diabetes medications as monotherapy or metformin-based combination therapy for type 2 diabetes: a systematic review and meta-analysis. Ann Intern Med 2016;164:740-751.

7. Mishriky BM, Cummings DM, Tanenberg RJ. The efficacy and safety of $\mathrm{DPP}_{4}$ inhibitors compared to sulfonylureas as add-on therapy to metformin in patients with type 2 diabetes: a systematic review and meta-analysis. Diabetes Res Clin Pract 2015;109:378-388.

8. Palmer SC, Mavridis D, Nicolucci A, et al. Comparison of clinical outcomes and adverse events associated with glucose-lowering drugs in patients with type 2 diabetes: a meta-analysis. JAMA 2016;316:313-324.

9. Zhou JB, Bai L, Wang Y, Yang JK. The benefits and risks of DPP4-inhibitors vs. sulfonylureas for patients with type 2 diabetes: accumulated evidence from randomised controlled trial. Int J Clin Pract 2016;70:132-141.

10. Foroutan N, Muratov S, Levine M. Safety and efficacy of dipeptidyl peptidase-4 inhibitors vs sulfonylurea in metformin-based combination therapy for type 2 diabetes mellitus: systematic review and meta-analysis. Clin Invest Med 2016;39:E48-E62.

11. Amate JM, Lopez-Cuadrado T, Almendro N, et al. Effectiveness and safety of glimepiride and $\mathrm{iDPP}_{4}$, associated with metformin in second line pharmacotherapy of type 2 diabetes mellitus: systematic review and meta-analysis. Int J Clin Pract 2015;69:292-304.

12. Seong JM, Choi NK, Shin JY, et al. Differential cardiovas- 
cular outcomes after dipeptidyl peptidase-4 inhibitor, sulfonylurea, and pioglitazone therapy, all in combination with metformin, for type 2 diabetes: a population-based cohort study. PLoS One 2015;10:e0124287.

13. Storgaard H, Gluud LL, Bennett C, et al. Benefits and harms of sodium-glucose co-transporter 2 inhibitors in patients with type 2 diabetes: a systematic review and meta-analysis. PLoS One 2016;11:eo166125.

14. Cefalu WT, Leiter LA, Yoon KH, et al. Efficacy and safety of canagliflozin versus glimepiride in patients with type 2 diabetes inadequately controlled with metformin (CANTATA-SU): 52 week results from a randomised, double-blind, phase 3 non-inferiority trial. Lancet 2013;382:941-950.

15. Nauck MA, Del Prato S, Meier JJ, et al. Dapagliflozin versus glipizide as add-on therapy in patients with type 2 diabetes who have inadequate glycemic control with metformin: a randomized, 52-week, double-blind, active-controlled noninferiority trial. Diabetes Care 2011;34:20152022.

16. Ridderstrale M, Andersen KR, Zeller C, et al. Comparison of empagliflozin and glimepiride as add-on to metformin in patients with type 2 diabetes: a 104-week randomised, active-controlled, double-blind, phase 3 trial. Lancet Diabetes Endocrinol 2014;2:691-700.

17. Zaccardi F, Webb DR, Htike ZZ, Youssef D, Khunti K, Davies MJ. Efficacy and safety of sodium-glucose co-transporter-2 inhibitors in type 2 diabetes mellitus: systematic review and network meta-analysis. Diabetes Obes Metab 2016;18:783-794.

18. Yoon KH, Nishimura R, Lee J, et al. Efficacy and safety of empagliflozin in patients with type 2 diabetes from Asian countries: pooled data from four phase III trials. Diabetes Obes Metab 2016;18:1045-1049.

19. Haring HU, Merker L, Seewaldt-Becker E, et al. Empagliflozin as add-on to metformin in patients with type 2 diabetes: a 24-week, randomized, double-blind, placebo-controlled trial. Diabetes Care 2014;37:1650-1659.

20. Min KW, Ku BJ, Lee JH, et al. Addition of ipragliflozin to metformin treatment in Korean patients with type 2 diabetes mellitus: subgroup analysis of a phase 3 trial. Diabetes Metab J 2017;41:135-145.

21. Lavalle-Gonzalez FJ, Januszewicz A, Davidson J, et al. Efficacy and safety of canagliflozin compared with placebo and sitagliptin in patients with type 2 diabetes on background metformin monotherapy: a randomised trial.
Diabetologia 2013:56:2582-2592.

22. Rosenstock J, Aggarwal N, Polidori D, et al. Dose-ranging effects of canagliflozin, a sodium-glucose cotransporter 2 inhibitor, as add-on to metformin in subjects with type 2 diabetes. Diabetes Care 2012;35:1232-1238.

23. Rosenstock J, Hansen L, Zee P, et al. Dual add-on therapy in type 2 diabetes poorly controlled with metformin monotherapy: a randomized double-blind trial of saxagliptin plus dapagliflozin addition versus single addition of saxagliptin or dapagliflozin to metformin. Diabetes Care 2015;38:376-383.

24. DeFronzo RA, Lewin A, Patel S, et al. Combination of empagliflozin and linagliptin as second-line therapy in subjects with type 2 diabetes inadequately controlled on metformin. Diabetes Care 2015;38:384-393.

25. Scirica BM, Bhatt DL, Braunwald E, et al. Saxagliptin and cardiovascular outcomes in patients with type 2 diabetes mellitus. N Engl J Med 2013;369:1317-1326.

26. White WB, Cannon CP, Heller SR, et al. Alogliptin after acute coronary syndrome in patients with type 2 diabetes. N Engl J Med 2013;369:1327-1335.

27. Green JB, Bethel MA, Armstrong PW, et al. Effect of sitagliptin on cardiovascular outcomes in type 2 diabetes. $\mathrm{N}$ Engl J Med 2015;373:232-242.

28. Zinman B, Wanner C, Lachin JM, et al. Empagliflozin, cardiovascular outcomes, and mortality in type 2 diabetes. N Engl J Med 2015;373:2117-2128.

29. Wanner C, Inzucchi SE, Lachin JM, et al. Empagliflozin and progression of kidney disease in type 2 diabetes. $\mathrm{N}$ Engl J Med 2016;375:323-334.

30. Neal B, Perkovic V, Mahaffey KW, et al. Canagliflozin and cardiovascular and renal events in type 2 diabetes. $\mathrm{N}$ Engl J Med 2017;377:644-657.

31. Kim YG, Hahn S, Oh TJ, Kwak SH, Park KS, Cho YM. Differences in the glucose-lowering efficacy of dipeptidyl peptidase-4 inhibitors between Asians and non-Asians: a systematic review and meta-analysis. Diabetologia 2013;56:696-708.

32. Hong AR, Lee J, Ku EJ, et al. Comparison of vildagliptin as an add-on therapy and sulfonylurea dose-increasing therapy in patients with inadequately controlled type 2 diabetes using metformin and sulfonylurea (VISUAL study): a randomized trial. Diabetes Res Clin Pract 2015;109:141-148.

33. Jin SM, Park SW, Yoon KH, et al. Anagliptin and sitagliptin as add-ons to metformin for patients with type 
2 diabetes: a 24-week, multicentre, randomized, double-blind, active-controlled, phase III clinical trial with a 28-week extension. Diabetes Obes Metab 2015;17:511-515.

34. Kim MK, Rhee EJ, Han KA, et al. Efficacy and safety of teneligliptin, a dipeptidyl peptidase-4 inhibitor, combined with metformin in Korean patients with type 2 diabetes mellitus: a 16-week, randomized, double-blind, placebo-controlled phase III trial. Diabetes Obes Metab 2015;17:309-312.

35. Kim JH, Kim SS, Baek HS, et al. Comparison of vildagliptin and pioglitazone in Korean patients with type 2 diabetes inadequately controlled with metformin. Diabetes Metab J 2016;40:230-239.

36. Jin SM, Park CY, Cho YM, et al. Lobeglitazone and pioglitazone as add-ons to metformin for patients with type 2 diabetes: a 24-week, multicentre, randomized, double-blind, parallel-group, active-controlled, phase III clinical trial with a 28 -week extension. Diabetes Obes Metab 2015;17:599-602.

37. Dormandy JA, Charbonnel B, Eckland DJ, et al. Secondary prevention of macrovascular events in patients with type 2 diabetes in the PROactive Study (PROspective pioglitAzone Clinical Trial In macroVascular Events): a randomized controlled trial. Lancet 2005;366:1279-1289.

38. Kahn SE, Haffner SM, Heise MA, et al. Glycemic durability of rosiglitazone, metformin, or glyburide monotherapy. N Engl J Med 2006;355:2427-2443.

39. Kahn SE, Lachin JM, Zinman B, et al. Effects of rosiglitazone, glyburide, and metformin on $\beta$-cell function and insulin sensitivity in ADOPT. Diabetes 2011;60:1552-1560.

40. Mamza J, Mehta R, Donnelly R, Idris I. Important differences in the durability of glycaemic response among second-line treatment options when added to metformin in type 2 diabetes: a retrospective cohort study. Ann Med 2016;48:224-234.

41. Downes MJ, Bettington EK, Gunton JE, Turkstra E. Triple therapy in type 2 diabetes: a systematic review and network meta-analysis. PeerJ 2015;3:e1461.

42. Lee CM, Woodward M, Colagiuri S. Triple therapy combinations for the treatment of type 2 diabetes: a network meta-analysis. Diabetes Res Clin Pract 2016;116:149-158.

43. Lozano-Ortega G, Goring S, Bennett HA, Bergenheim K, Sternhufvud C, Mukherjee J. Network meta-analysis of treatments for type 2 diabetes mellitus following failure with metformin plus sulfonylurea. Curr Med Res Opin 2016;32:807-816.

44. Mearns ES, Saulsberry WJ, White CM, et al. Efficacy and safety of antihyperglycaemic drug regimens added to metformin and sulphonylurea therapy in type 2 diabetes: a network meta-analysis. Diabet Med 2015;32:1530-1540.

45. Ahn CH, Han KA, Yu JM, et al. Efficacy and safety of gemigliptin, a dipeptidyl peptidase- 4 inhibitor, in patients with type 2 diabetes mellitus inadequately controlled with combination treatment of metformin and sulphonylurea: a 24-week, multicentre, randomized, double-blind, placebo-controlled study (TROICA study). Diabetes Obes Metab 2017;19:635-643. 